NBER WORKING PAPER SERIES

\title{
STEMMING THE TIDE? \\ THE EFFECT OF EXPANDING MEDICAID \\ ELIGIBILITY ON HEALTH INSURANCE
}

Lara D. Shore-Sheppard

Working Paper 11091

http://www.nber.org/papers/w11091

\author{
NATIONAL BUREAU OF ECONOMIC RESEARCH \\ 1050 Massachusetts Avenue \\ Cambridge, MA 02138 \\ January 2005
}

I am grateful to Lisa Barrow, Patricia Beeson, Kenneth Chay, David Cutler, Lisa Dubay, Henry Farber, Maria Hanratty, Helen Levy, Jeremy Rudd, Lucie Schmidt, and especially David Card for comments and advice. This paper has also benefitted from comments in seminars at Carnegie Mellon, Dartmouth, Houston, Maryland, Pittsburgh, Princeton, Illinois, UC Irvine, Wharton, Williams, and the Yale University School of Medicine. Jonathan Gruber and David Cutler graciously provided computer code that permitted me to replicate their results. This research was supported by a grant from the National Institute of Child Health and Human Development (Grant No. R01 HD39369-01A1), as well as funding from the Industrial Relations Section at Princeton University, the Joint Center for Poverty Research at the University of Chicago, and the Oakley Center for Humanities and Social Sciences at Williams. The views expressed herein are those of the author(s) and do not necessarily reflect the views of the National Bureau of Economic Research.

(C) 2005 by Lara D. Shore-Sheppard. All rights reserved. Short sections of text, not to exceed two paragraphs, may be quoted without explicit permission provided that full credit, including $\odot$ notice, is given to the source. 
Stemming the Tide? The Effect of Expanding Medicaid Eligibility on Health Insurance Lara D. Shore-Sheppard

NBER Working Paper No. 11091

January 2005

JEL No. I1

\begin{abstract}
Despite considerable research, there is little consensus about the impact of Medicaid eligibility expansions for low-income children. In this paper, I reexamine the expansions' impact on Medicaid take-up and private insurance "crowd-out." Focusing on the most influential estimates of the expansions' impact, I show that while many of the critiques leveled at these estimates have little effect on their magnitude, accounting for age-specific trends in coverage produces estimates similar to others in the literature. Estimating the impact of later expansions using additional years of data, I find low rates of take-up and no evidence of crowding out.
\end{abstract}

\author{
Lara D. Shore-Sheppard \\ Department of Economics \\ Williams College \\ 34 Sawyer Library Drive \\ Williamstown, MA 01267 \\ and NBER \\ lshore@williams.edu
}




\section{Introduction}

Although per capita health care expenditures in the United States are among the highest in the world, a substantial fraction of the U.S. population — mainly lower-income families — lack health insurance coverage. ${ }^{1}$ In 1965 , the Medicaid program was established to address the problem of health insurance coverage for the poor. Though it began as a narrowly-targeted program for welfare recipients and the aged or disabled poor, starting in the 1980s Medicaid eligibility standards were liberalized for two groups: poor children and pregnant women. A series of federal laws broke the link between Medicaid and welfare receipt, raising the family income limit for Medicaid coverage and extending eligibility to children in two-parent families.

As would be expected for a program that has experienced such substantial changes, the impact of the Medicaid expansions has elicited great research interest. A particularly intense focus of research has been the expansions' impact on insurance coverage, including the rate at which eligible children enrolled in the program (the take-up rate) and to what extent expanded public provision of insurance through Medicaid caused "crowding out" of private coverage. As the option of Medicaid coverage is extended to children who were not previously eligible for the program, the take-up rate is a key indicator of whether the program is reaching its intended beneficiaries. However, some newly eligible children may drop existing private coverage to enroll in Medicaid. This movement from private to publicly-provided coverage is not necessarily a policy failure, as the families of these low-income children presumably would be able to use the funds that had previously gone to the purchase of health insurance to purchase other goods. Nevertheless, policy makers are keenly interested in crowding out as well as take-

\footnotetext{
${ }^{1}$ In 2001 expenditures on health by the nation as a whole were $\$ 1.4$ trillion, or 14 percent of GDP, however close to 15 percent of the population was without coverage (U.S. Census Bureau, 2003).
} 
up, since to the extent such movement takes place, the increase in the number of children with health insurance will not be commensurate with the increase in the number of children on Medicaid.

From the beginning, these questions have produced more disagreement than consensus. In a seminal paper, Cutler and Gruber (1996) estimated take-up rates of about 24 percent among newly eligible children, but found crowd-out propensities of about 7 percent. Other researchers found smaller estimates of both take-up and crowding out, though these estimates also vary (e.g. Dubay and Kenney (1996), Shore-Sheppard (2000), Yazici and Kaestner (2000), Blumberg, Dubay, and Norton (2000), Ham and Shore-Sheppard (2005), Card and Shore-Sheppard (2004)). The substantial difference between Cutler and Gruber's estimates of crowding out and the estimates of many other researchers has given rise to many critiques of Cutler and Gruber's work. The resulting debate over the merit of various critiques and the likely magnitude of the effects of the Medicaid expansions has left readers of the literature more confused than enlightened.

In this paper, I use data from the March Current Population Survey (CPS) to reexamine the Medicaid expansions and clear up the confusion surrounding their impact. The primary difficulty in evaluating the Medicaid expansions lies in the fact that other changes in the economy may affect health insurance coverage. For example, worsening economic conditions and increasing health insurance costs are likely to result in higher levels of Medicaid coverage and lower levels of private health insurance coverage independent of the expansions. I begin by illustrating the main components of the rise in eligibility that took place among children between 1988 (before the expansions were implemented) and 1996 (prior to the implementation of the State Children's Health Insurance Program, or SCHIP, which further liberalized eligibility 
standards), outlining the sources of variation that can be used to identify a causal effect of the expansions. I then use Cutler and Gruber's specification as a basis for new estimates of the expansions' impact. I find that while accounting for many of the critiques leveled at these estimates has little effect on their magnitude, when the possibility of age-specific trends in insurance coverage is accounted for, their approach produces much smaller estimates of marginal take-up rates and no statistically significant evidence of crowding out. The estimates of take-up and crowd-out propensities are particularly small when later years of data, incorporating the effects of state-optional expansions, are included. I examine whether the small estimated takeup rates can be attributed to measurement error in the data, and find that even accounting for measurement error, a substantial portion of the increase in Medicaid coverage is unexplained by the eligibility expansions.

\section{Expansions of the Medicaid Program}

\section{A. Legislative Background}

Medicaid is a joint state-federal program financed by state contributions and federal matching funds. Program participants fall into three groups: the low-income aged, the lowincome disabled, and low-income families with dependent children. Members of the third group were the main focus of the legislative changes beginning in 1986, and in this paper I concentrate exclusively on them. Historically, Medicaid eligibility and participation were directly linked to the eligibility standards for the Aid to Families with Dependent Children (AFDC) program. Generally, to qualify for AFDC a family must have been either headed by a single parent or have an unemployed primary earner, and was required to pass stringent income and resource tests.

Starting in the late 1980 's, a series of changes in federal law substantially diminished the 
link between Medicaid eligibility and AFDC eligibility by extending Medicaid coverage to families with incomes above the AFDC thresholds (a detailed list of the expansions is provided in Appendix Table 1). ${ }^{2}$ Beginning with the Omnibus Budget Reconciliation Acts (OBRA) of 1986 and 1987, Congress gave states the authority to raise the income limits for Medicaid coverage of certain groups (such as infants and very young children) above the AFDC level. Congressionally mandated increases in state eligibility limits followed, most notably with the passage of OBRA 1989 and OBRA 1990. OBRA 1989 required coverage of pregnant women and children up to age 6 with family incomes up to 133 percent of the federal poverty level, and OBRA 1990 required states to cover children born after September 30, 1983 with family incomes below 100 percent of the federal poverty level. Further expansions within certain guidelines for age and family income were permitted at state option. In total, the expansions raised the eligibility threshold from the AFDC level (typically well below the poverty line) to at least 100 percent of the poverty line and possibly higher, depending on the child's age and state of residence.

\section{B. Data Used to Measure the Impact of the Expansions}

The data used in this paper are for all children (age 18 and under) from the CPS March supplements for 1988-1996. In addition to the usual demographic and labor force data, the March supplements provide information on respondents' income sources, household composition, and participation in government programs, including government health programs. The detailed family income and family structure data in the March CPS make it possible to

\footnotetext{
${ }^{2}$ Until the expansions, the primary group eligible for Medicaid but ineligible for AFDC had been "Ribicoff children." These are children who are financially eligible for AFDC but do not qualify due to family structure-e.g., they are from two-parent families or they are in privately subsidized foster care.
} 
impute eligibility for the Medicaid program. Another advantage of the CPS is its size and scope of coverage: there are approximately 40,000 children in each year of data, and all states are represented. ${ }^{3}$

Since one of the goals of the paper is to replicate and to reexamine Cutler and Gruber's estimates, I follow their sample selection criteria. This results in a sample of 266,421 children from the 1988-1993 CPS, and 391,964 from the 1988-1996 surveys. I also follow Cutler and Gruber's algorithm for imputing eligibility according to a child's age, family income and structure, state of residence, and applicable laws. ${ }^{4}$

Descriptive statistics for the sample are presented in Table 1. Basic characteristics of the children such as the distribution of age and region of residence change little over the period, as would be expected. The fraction of children in single-parent families rises over the period, however, and the fraction of children in poverty, the fraction receiving AFDC, and the fraction covered by Medicaid also rise between 1987 and 1993, falling slightly thereafter. ${ }^{5}$ The statistics

${ }^{3}$ Despite the advantages of the CPS data, several researchers have questioned the March CPS measure of health insurance coverage (see e.g. Swartz 1986, Office of Technology Assessment 1988, and Ku, Ellwood, and Klemm 1990). In particular, CPS estimates of Medicaid enrollment have been found to be too low when compared with the estimates from other data sources. In previous work (Shore-Sheppard 1996a) I examine the appropriateness of using the CPS for research on health insurance by comparing the March 1988 CPS with the 1987 National Medical Expenditure Survey and the March 1993 CPS with the April 1993 CPS. Based on these comparisons, I conclude that the March CPS surveys provide a reasonable source of Medicaid coverage rates, and that the coverage measures in the March CPS can be interpreted as point-intime coverage rates as of a window between December and March.

${ }^{4}$ I tested many different assumptions about the timing of the expansions and children's ages and birth dates in the CPS, and the results changed very little. I also tried eliminating children in families with more than nine members, because information on state AFDC standards is missing for these families (Cutler and Gruber's algorithm assumes that all such families are incomeeligible for AFDC). Eliminating these children also yields very similar results.

${ }^{5}$ The apparent time trend in the CPS coverage measures after 1993 (1994 CPS) may be slightly misleading, since as discussed by Swartz (1997), in 1995 the Census Bureau introduced 
in Table 1 lead to two main conclusions. First, as suggested by the rise in the percentage of children in female-headed families and the rising fraction of children in families with incomes below or near the poverty line, children in the U.S. suffered a modest worsening in family circumstances between 1987 and 1993. Following that period, family circumstances improved slightly as the economy improved. Second, the percentage of children covered by Medicaid rose sharply over the period, and substantially faster than the fraction on AFDC.

\section{The Sources of Variation in Eligibility}

The form of the expansions produced variation in eligibility along several dimensions: over time as the expansions were phased in, across states because of existing variation in AFDC (and hence Medicaid) eligibility limits and because states had the option of exceeding the federal minimum eligibility limits, across ages because eligibility standards for younger children were generally less restrictive, and across income levels, with poorer children having a greater likelihood of coverage. Such differences in eligibility provide plausibly exogenous variation that can be used to identify the effects of the expansions.

The impact of the expansions on eligibility over time is illustrated in Figure 1, which shows the change in eligibility between 1987 and 1995 (as measured in the 1988-1996 March CPS). Since population characteristics may be changing over time in ways that affect eligibility, I show two counterfactual eligibility trends in addition to the actual changes in eligibility: the

\section{5 (...continued)}

several changes in the March CPS, including changes in the order and wording of the health insurance questions and the customary mid-decade shift of the sample frame to accord with the results from the decennial census. In a thorough examination of the changes and their effects, Swartz notes that the shift in the sample framework appears to have affected estimated Medicaid enrollment, yielding a potentially misleading break in the trend. It is interesting to note, however, that rather than 1994, 1993 appears to be something of an outlier in the Medicaid trend, with 1994 and 1995 returning to previous levels. 
eligibility levels that would have occurred given the changes in the rules if population characteristics remained what they were in 1987 , and the eligibility levels that would have occurred given changes in population characteristics holding eligibility criteria constant at their 1987 levels. It is clear from the graph that the legislated expansions played an important role in the eligibility increase, since in their absence eligibility would have risen slightly during the 1989-1991 recession but would otherwise have remained flat, dipping somewhat at the end of the period. Instead, eligibility rose almost monotonically from 1989 to 1993, a trend that would have occurred even if the population characteristics had remained unchanged. The divergence of the actual eligibility trend from the constant-population eligibility trend from 1990 to the end of the period can be attributed to an increase in the fraction of children meeting the new eligibility criteria, though not the old ones.

Table 2 provides a breakdown of the programs contributing to the rise in eligibility by year, using the eligibility of the constant 1987 population to isolate the changes due solely to the laws. ${ }^{6}$ The second column shows the overall percent eligible, and corresponds to the dotted line in Figure 1. Eligibility through AFDC (or a program requiring the child to meet AFDC income standards) changes slightly only as state AFDC income limits change, but is otherwise stable, remaining the primary source of eligibility throughout the period. The Medicare Catastrophic Coverage Act (MCCA, which provided eligibility for infants) is so small that it has little effect on overall eligibility. OBRA 1989 increased eligibility significantly beginning in 1990, while OBRA 1990 began its phase-in in 1991. State optional programs had relatively little effect on eligibility prior to 1992, but played a more significant role at the end of the period.

\footnotetext{
${ }^{6}$ Children are assigned to the most restrictive category for which they are eligible. Children who are eligible under both the OBRA 1989 and OBRA 1990 expansions are assigned OBRA 1989 eligibility. State program eligibility is assigned last.
} 
Most of the state options and OBRA 1990 applied only to children born after September 30, 1983, and OBRA 1989 applied only to children under age 6. Consequently, the rise in eligibility was not constant across ages (or birth cohorts). Figure 2 shows the trends in Medicaid eligibility by age between 1987 and 1995. As would be expected given the form of the expansions, there is a general pattern of higher eligibility for younger ages. The impact of the OBRA 1989 expansion can be seen clearly, as trends in eligibility for children younger and older than 6 diverge substantially between 1989 and 1990. The impact of the OBRA 1990 expansion can also be seen, as eligibility levels for older children rise after 1991 as the expansion is phased in.

Figure 3 shows corresponding patterns of Medicaid coverage by age. In this graph the impact of the expansions is much more difficult to discern. As in the previous figure, younger children have higher levels of coverage than older ones, however coverage rates are much flatter than eligibility rates, with little evidence of a jump in coverage as would be expected given the substantial increase in eligibility. There is little divergence between children older and younger than 6, indicating that the OBRA 1989 expansions may have had relatively little effect on coverage. ${ }^{7}$ Moreover, the increase in coverage rates for children older than 6 after 1990 is slight. It is also interesting to note that coverage rates of different age groups follow different trends, with some rising more steeply and some remaining flatter. While some of these differences are likely to be a result of the age differences in the expansions, it is possible that underlying changes in the economy may be affecting coverage rates of different aged children differently. This possibility is evident in the 1987-1989 period, which precedes most expansions except

\footnotetext{
${ }^{7}$ The difference between eligibility and coverage patterns following OBRA 1989 is even more clear in graphs by cohort, which show a sharp drop in eligibility as each cohort passes through age 6 , but no such drop in Medicaid coverage.
} 
those affecting very young or very poor children. During this period, coverage rates of some groups rose, while others fell, and still others remained flat.

Figures 4 and 5 illustrate similar comparisons for eligibility and coverage levels by state for five populous states. ${ }^{8}$ Prior to the federally mandated expansions, the threshold for eligibility varied widely among states due to the large variation in state AFDC eligibility levels. By 1991, all states had raised their eligibility levels in response to the congressional mandate. Some states were forced to raise their eligibility standards by more than others to comply with the federal guidelines. For example, to meet the federal minimum of 133 percent of the poverty threshold for children under 6 years of age, Alabama had to increase its eligibility level 775 percent, while Utah only had to raise its eligibility level 49 percent. In addition, some states chose to implement optional expansions, particularly in the 1993-1995 period, while others did not. Such differences are illustrated in Figure 4. California and New York had relatively high eligibility levels prior to the expansions, both because they had relatively generous AFDC programs, and because they had relatively large numbers of poor children. Both states also showed a substantial jump in eligibility in the early 1990s, particularly California. While the other three states' initial eligibility levels are more similar, trends do vary across the states. New Jersey's eligibility level remained relatively flat throughout the period, while both Texas and Florida showed gradual but steady increases in eligibility. These varying trends can be attributed to the factors outlined above: differences in state AFDC policies, differences in state optional program legislation (the primary explanation for California's jump between 1992 and 1994), and

${ }^{8}$ Only five states are shown to ensure clarity in the figure. Large states were chosen because their estimates are the most precise. 
differences in state economic environments. ${ }^{9}$

While variation in eligibility across states and within state over time is substantial for these five states, the variation in Medicaid coverage rates is much lower (Figure 5). Coverage rates generally increase over the period, but much more slowly than eligibility rates. This is particularly the case in the initially high-coverage states (New York and California). ${ }^{10}$ Florida and Texas show more rapid coverage increases, particularly post-1990, leading to some convergence with the initially higher-coverage states. New Jersey's coverage pattern most closely tracks its eligibility pattern, both showing little variation over the period. Across all five states, coverage rates flatten or even turn downward after 1993.

Overall, Figures 1-5 show considerable variation in eligibility over time, across ages, by age over time, across states, and within states over time. These sources of variation are important in identifying the expansions' impact. The substantial increases in eligibility do not appear to be matched by similar increases in coverage, however, which is consistent with

${ }^{9}$ In addition to the federally mandated and optional expansions in Medicaid, some states used state funds to expand health insurance to children not covered by the expansions. These statefunded programs complicate the evaluation of the Medicaid expansions as it is unclear whether they should be included in the eligibility simulation. If a state makes a distinction between Medicaid and its state-sponsored program that residents are aware of, then CPS respondents whose children were enrolled in the state-sponsored program would not report having Medicaid coverage. In that case, the state programs should not be included. If a state makes no distinction between the programs, then the state-sponsored program should be included in the eligibility imputation. One potential problem with including the state-sponsored programs in the eligibility simulation is that while the federal mandate to expand Medicaid is plausibly a source of exogenous variation, the variation due to state programs may be endogenous. For example, states experiencing larger decreases in private coverage may be more likely to implement a statefunded program. I include state programs in the eligibility simulation primarily because it is difficult to disentangle whether the state is paying for coverage. If state-funded programs are omitted, the results are quite similar.

${ }^{10}$ The absence of a coverage jump in California is evident in administrative data as well as in the CPS (see Card, Hildreth, and Shore-Sheppard 2004). 
findings of relatively low take-up of the expansions. In the next section, I estimate marginal rates of take-up and rates of crowd-out more formally.

\section{Estimates of the Expansions' Impact}

Although the presence of treated and untreated groups in the population (such as 5-yearolds versus 6-year-olds) would seem to make identification of econometric estimates of the expansions' impact simple, there has nevertheless been a long-standing debate on the existence and magnitude of crowding out and take-up effects. Much of this debate has been focused on the estimates of Cutler and Gruber, the first published and most widely cited of all estimates. Cutler and Gruber find relatively large take-up and crowd-out effects, and the latter finding, in particular, has elicited considerable criticism. However, it is not clear which, if any, of these critiques have empirical merit. The key difficulty in evaluating the Cutler and Gruber estimates is that their approach combines many sources of variation. This is an econometric strength, but as a result, the source of the identification is not transparent. In this section, I analyze Cutler and Gruber's estimator, identify the sources of variation, and summarize some of the most prominent critiques. I then use the framework of Cutler and Gruber to provide estimates that are not subject to these critiques, for both the time period analyzed by Cutler and Gruber, and a longer time period that incorporates additional state-optional expansions.

\section{A. The Cutler and Gruber Estimates}

The basis for Cutler and Gruber's estimates of the impact of the expansions is the relationship between a child's insurance status and his or her Medicaid eligibility status:

$$
\text { Covg }_{\text {iast }}{ }^{\prime} \alpha \% \beta \text { Elig }_{\text {iast }} \% \varepsilon_{\text {iast }} .
$$

In this regression, $\operatorname{Covg}_{\text {iast }}$ is an indicator for insurance coverage status (Medicaid, private, or no 
insurance) for child $i$ of age $a$ from state $s$ in year $t$, Elig $_{\text {iast }}$ is a dummy indicating eligibility for Medicaid, and $\varepsilon_{\text {iast }}$ is an error term. Cutler and Gruber's goal is to obtain an unbiased, causal estimate of $\beta$. When Medicaid coverage is the dependent variable, $\beta$ measures the extent of Medicaid take-up, and when private coverage is the dependent variable $\beta$ measures private coverage crowd-out. ${ }^{11}$ In addition to being the basic relationship underlying the work of Cutler and Gruber, it is also the relationship underlying virtually all of the work done on the coverage impacts of the expansions. In work by other researchers this regression has often been estimated for groups rather than at the individual level. ${ }^{12}$

As all researchers of the expansions have recognized, simply estimating (1) will not yield an unbiased, causal estimate of the expansions' impact. First, factors affecting eligibility (parental earnings ability or employment status, for example) are likely to be correlated with determinants of coverage status. Since many of these determinants of eligibility are unobserved, Elig is likely to be endogenous. AFDC remained the main source of eligibility throughout the period, so children whose mothers qualified for AFDC would both be eligible and have a high probability of Medicaid coverage and a low probability of private coverage. Second, there are many other factors affecting Medicaid and private coverage, including varying insurance

\footnotetext{
${ }^{11}$ The ratio of the two estimates, $\hat{\beta}^{\text {Priv }} / \hat{\beta}^{\text {Med }}$, is used by Cutler and Gruber to measure the fraction of children enrolling in Medicaid as a result of the expansions who came from private coverage. This number has often been misinterpreted by readers of the literature to be measuring the portion of the reduction in private coverage over the period attributable to Medicaid expansions.

${ }^{12}$ Many researchers use a "difference in differences" methodology, defining a "treatment" group to be one which experienced an increase in eligibility and a "control" group to be one which did not experience an increase in eligibility, but which experienced the same other conditions as the treatment group. While this strategy is not strictly the same as a strategy involving estimation of a version of (1), it is intended to elicit information about the same behavioral parameter, $\beta$.
} 
markets by state, changes in the economy, and changes in the availability of private insurance for various groups. If these factors are not accounted for, the estimates of $\beta$ will be biased.

To address these problems, Cutler and Gruber estimate the relationship in (1) using instrumental variables. Their instrument for individual eligibility is the average eligibility rate of a nationally representative sample of children of age $a$ under the laws in effect in state $s$ in year $t$, Simelig $_{\text {ast. }}$ The requirement that the instrument be correlated with Elig is easily satisfied, as children in state-year-age cells with higher eligibility rates would be more likely to be eligible themselves, relative to children in cells with low eligibility rates. This instrument uses variation in eligibility by state-year-age cell that occurs because of the reasons outlined in the discussion of the figures to identify the effect of eligibility, and is thus arguably exogenous. This is particularly the case for federal expansions that forced states to meet eligibility requirements for certain age groups. Some of the expansions were enacted at state option, however, so it is possible that states targeted groups experiencing worse economic conditions, making the state expansions potentially endogenous. It is also possible that groups experiencing worse economic conditions happened to be those particularly affected by the expansions, even though the legislation was not intentionally aimed to mitigate economic conditions for these groups.

In an attempt to address these concerns, Cutler and Gruber modify (1) further by including additional control variables:

$$
\text { Covg }_{\text {iast }}{ }^{\prime} \quad \alpha_{0} \% \beta \text { Elig }_{\text {iast }} \% X_{\text {iast }} \gamma \%{ }_{s} \alpha_{s} \text { state }_{\text {iast }} \% \mathrm{j}_{t} \alpha_{t} \text { year }{ }_{\text {iast }} \%{ }_{a} \alpha_{a} \text { age }_{\text {iast }} \% \varepsilon_{\text {iast }},
$$

where $X_{\text {iast }}$ is a set of observed characteristics of the individual (including demographic characteristics), and state, year, and age are sets of indicator variables. State effects are included to account for differences in coverage across states unrelated to the expansions. Time effects are included to control for macroeconomic shocks and economy-wide trends such as changes in the 
price of health insurance that would tend to change coverage rates even in the absence of the expansions. Finally, age effects account for the possibility of differential coverage rates unrelated to the expansions-for example, younger children may have lower private coverage rates and higher Medicaid coverage rates, perhaps because on average they have younger parents, who tend to have lower earnings.

To estimate (2), Cutler and Gruber use samples of all children under 18 in the March 1988-1993 Current Population Surveys. Linear probability model estimates of (2) from Table IV of their paper are shown in the top row of Table 3. The first column reports estimates of the take-up rate for Medicaid coverage, the second column reports estimates of the crowd-out rate of private insurance, and the third column presents estimates of the effect on the likelihood of being uninsured. My replications of Cutler and Gruber's estimates are reported in the second row of Table 3. I obtain estimates of $\beta$ that vary only slightly from Cutler and Gruber's estimates. ${ }^{13}$ Their estimates indicate that the marginal take-up rate among children who became eligible over the 1988-1993 period was 24 percent, while the crowd-out rate was 7 percent. The overall reduction in the propensity to be uninsured among the eligible is estimated to be 12 percent (this estimate does not equal the sum of the take-up and crowd-out effects because of changes in the propensity to report both Medicaid and private coverage during the year).

\section{B. Analysis of Cutler and Gruber's Estimator}

To ensure that the estimated $\beta$ actually measures the effect of the expansions, other

\footnotetext{
${ }^{13}$ Since the instrument varies only at the group level rather than at the individual level the errors are likely to be understated. However there are many groups in the data, so the degree of understatement is small (Shore-Sheppard 1996b). As estimating the standard errors accounting for their group structure increases their magnitude only slightly (from 0.016 to 0.020 , for example), to ease comparisons with Cutler and Gruber's estimates I use uncorrected standard errors in the paper. Corrected versions are available upon request.
} 
possible sources of coverage changes must be ruled out. The primary criticism leveled at Cutler and Gruber's estimator is that it does not eliminate the influence of other trends, although commentators differ on which trends are important. A common concern (see, for example, Swartz (1996) and Yazici and Kaestner (2000)) is that states that were particularly hard hit by the recession (and thus suffered larger private coverage losses) were ones that had larger eligibility increases. In the context of Cutler and Gruber's model, this critique questions the omission of state by year effects. Omitting these effects restricts trends in coverage in different states to be the same in the absence of the expansions, but as different states have different insurance markets and different industrial structures, they may be affected differently by macroeconomic shocks or insurance industry changes. Estimates including state by year effects are shown in the third row of Table 3. They are essentially the same as the estimates that do not allow for separate trends by state, so while valid theoretically, empirically this critique does not explain the relatively large take-up and crowd-out rates found by Cutler and Gruber.

As discussed in Section II, much of the identification of the expansions' impact comes from changes in eligibility by age over time. This is primarily because of the form of the expansions, which targeted younger children and imposed arbitrary cutoffs (e.g. birthday prior to October 1983, age less than 6). However changes in coverage over time for children of different ages can occur for reasons other than the expansions. For example, younger workers (who tend to have younger children) may be losing access to private coverage at a faster rate than older workers, or may be differentially hit by recessionary shocks. Thus as Card and Shore-Sheppard (2004) note, trends in coverage by age need not have been the same in the absence of the expansions. To account for the possibility of differential trends by age and to narrow the source of identification to changes in eligibility by age over time occurring because of the expansions, 
age by year effects can be included in the model. The fourth row of Table 3 shows estimates from a model including age by year effects. Unlike the previous change, this addition has a substantial impact on the estimates of take-up and crowd-out. The take-up estimate is reduced by half, to 15 percent. The point estimate of the crowd-out effect is 1 percent, but it is not statistically different from $0 .^{14}$

The final set of two-way interactions omitted from Cutler and Gruber's model is a set of age by state effects. Omitting these effects restricts coverage rates for children of the same age living in different states to be the same in the absence of the expansions. Since states vary in industrial structures and economic conditions, it is possible that this restriction is invalid. In the fifth row of Table 3 I remove this restriction by including age by state effects in the model. The results are essentially the same as when they are omitted.

In the final row of the top panel of the table, all three two-way interactions are included in the model. In this case, the identification comes from the three-way interaction between state, year, and age. The coefficients are between the coefficients obtained from models with and without age by year interactions, though they are less precise. Thus it appears that both take-up and crowd-out propensities are much smaller than Cutler and Gruber's estimates would indicate once the restriction on age effects has been removed.

A second common critique of the Cutler-Gruber estimator is that it produced larger estimates of crowding out because Cutler and Gruber used the entire sample of children, even

${ }^{14}$ The $\mathrm{p}$-value on the F-test that the age by year interactions are jointly equal to 0 is 0.00 for the Medicaid equation, 0.16 for the private equation, and 0.33 for the uninsured equation. However, if ages are grouped into categories based on the cutoffs of the expansions (0-2, 3-5, 6$8,9-11,12-14$, and $15+)$ the resulting coefficients on eligibility change very little but the pvalues on the F-test drop substantially. For Medicaid: coeff. $=0.169(0.027) p=0.00$; for private: coeff. $=-0.023(0.034) \mathrm{p}=0.01$; and for uninsured: coeff. $=-0.109(0.029) \mathrm{p}=0.01$. 
those too well-off to be eligible for Medicaid (see, for example, Dubay and Kenney (1996) and Yazici and Kaestner (2000)). While children too well-off to be eligible for Medicaid are not serving as a "control group," their presence in the sample will affect the estimates, though to a relatively small degree. To see how using the entire sample of children affects the estimates of $\beta$, consider a version of Cutler and Gruber's model without covariates (replacing Covg with $Y$ and Elig with $X$ to simplify the notation):

(3) $\quad Y^{\prime} \alpha \% \beta X \% \varepsilon$.

The model is estimated using instrumental variables, where the instrument is Simelig (denoted $Z$ ). The sample of all children can be divided into two groups: those with family incomes below 300 percent of the poverty line, who have some probability of being eligible depending on their ages and the rules in their states (subsample 1), and those with family incomes above 300 percent of the poverty line, who are ineligible for Medicaid (subsample 2).

Using the low-income subsample yields an estimate $\hat{\beta}_{1}{ }^{\prime} \operatorname{Cov}\left(Y_{1}, Z_{1}\right) / \operatorname{Cov}\left(X_{1}, Z_{1}\right)$ (subscripts indicate the values come from the poor subsample), while using the entire sample yields an estimate $\hat{\beta}_{12}{ }^{\prime} \operatorname{Cov}(Y, Z) / \operatorname{Cov}(X, Z)$. The covariance between $Y$ and $Z$ in the entire sample can be written as a combination of covariances involving the subsamples:

$$
\operatorname{Cov}(Y, Z)^{\prime} \frac{N_{1}}{N} \operatorname{Cov}\left(Y_{1}, Z_{1}\right) \% \frac{N_{2}}{N} \operatorname{Cov}\left(Y_{2}, Z_{2}\right) \% \frac{N_{1}}{N}\left(\bar{Y}_{1} \& \bar{Y}\right) \bar{Z}_{1} \% \frac{N_{2}}{N}\left(\bar{Y}_{2} \& \bar{Y}\right) \bar{Z}_{2}
$$

where $\mathrm{N}_{1}$ and $\mathrm{N}_{2}$ are the number of observations in each subsample, $\mathrm{N}$ is the total number of observations, $\mathrm{Z}_{\mathrm{i}}$ and $\mathrm{Y}_{\mathrm{i}}$ denote $\mathrm{Z}$ 's and $\mathrm{Y}^{\prime} \mathrm{s}$ in the respective subsamples $(\mathrm{i}=1,2)$, and bars denote means-either the overall mean when there is no subscript, or the subsample mean when there is a subscript. Similarly, 


$$
\operatorname{Cov}(X, Z)^{\prime} \frac{N_{1}}{N} \operatorname{Cov}\left(X_{1}, Z_{1}\right) \% \frac{N_{2}}{N} \operatorname{Cov}\left(X_{2}, Z_{2}\right) \% \frac{N_{1}}{N}\left(\bar{X}_{1} \& \bar{X}\right) \bar{Z}_{1} \% \frac{N_{2}}{N}\left(\bar{X}_{2} \& \bar{X}\right) \bar{Z}_{2}
$$

The first two terms of each covariance are each "within subsamples" covariances. The second two terms together are the "between subsamples" covariance. $\hat{\beta}_{12}$, the estimate from the overall sample, is the ratio of (4) to (5), $\hat{\beta}_{1}$, the estimate from the poor sample, is the ratio of the first term from (4) to the first term from (5), and $\hat{\beta}_{2}$, the estimate from the non-poor sample, is the ratio of the second term from (4) to the second term from (5).

If there is no covariance between variables in the subsamples (that is, the last two terms in (4) and (5) are 0) then $\hat{\beta}_{12}$ can be written as a linear combination of $\hat{\beta}_{1}$ and $\hat{\beta}_{2}$ :

$$
\hat{\beta}_{12}{ }^{\prime} \frac{\frac{N_{1}}{N} \operatorname{Cov}\left(X_{1}, Z_{1}\right)}{\frac{N_{1}}{N} \operatorname{Cov}\left(X_{1}, Z_{1}\right) \% \frac{N_{2}}{N} \operatorname{Cov}\left(X_{2}, Z_{2}\right)} \hat{\beta}_{1} \% \frac{\frac{N_{2}}{N} \operatorname{Cov}\left(X_{2}, Z_{2}\right)}{\frac{N_{1}}{N} \operatorname{Cov}\left(X_{1}, Z_{1}\right) \% \frac{N_{2}}{N} \operatorname{Cov}\left(X_{2}, Z_{2}\right)} \hat{\beta}_{2} .
$$

$\hat{\beta}_{12}$ (Cutler and Gruber's estimate) will reduce to $\hat{\beta}_{1}$ (the estimate using only poor children) if there is no covariance between variables in the subsamples (so that (6) is valid) and if the covariance between $X$ (eligibility) and $Z$ (simulated eligibility of a random sample) is 0 in the non-poor sample (that is, $\operatorname{Cov}\left(X_{2}, Z_{2}\right)=0$ ). Since the eligibility of the random sample is only a function of age, state, and year, and does not vary with a child's family income, $Z_{2} \$ 0$, while $X_{2}$ is always 0 (the non-poor are not eligible). Thus the covariance between $X_{2}$ and $Z_{2}$ should be close to 0 . Similarly, it is unlikely that the covariance between variables in the subsamples would be substantial, although it would not necessarily be 0 . Consequently, one would expect $\hat{\beta}_{12}$ to deviate only slightly from $\hat{\beta}_{1}$, with the sources of the deviation being nonzero covariance 
between subsamples and nonzero covariance between $X$ and $Z$ in the non-poor sample.

Estimates using only children with family incomes below 300 percent of the poverty line (shown in the bottom panel of Table 3) bear out this prediction. When I replicate Cutler and Gruber's model in this sample, I find estimates of take-up and crowd-out propensities that are only slightly smaller than the estimates from the whole sample. Relaxing various restrictions by including sets of fixed effects produces similar patterns to those observed in the top panel of the table. In particular, relaxing the restriction on age by year effects reduces the estimated take-up and crowd-out effects to magnitudes that are similar to those found in the whole sample. As before, incorporating all three two-way interactions produces estimates that are between those with and without age by year interactions and have larger standard errors. The overall conclusions remain approximately the same: take-up rates are estimated to have been between 13 and 15 percent, with little evidence of crowd-out and a reduction in the propensity to be uninsured between 8 and 11 percent.

\section{Updated Estimates of the Impact of the Expansions}

The discussion of the impact of the Medicaid expansions thus far has proceeded under the implicit assumption that their impact was the same for everyone (that is, $\beta$ is a constant). Evidence in the literature suggests that this may not be the case. Card and Shore-Sheppard (2004) focus on the OBRA 1989 and OBRA 1990 expansions and find different effects of eligibility for children eligible through different expansions, with take-up effects ranging from close to 0 for children made eligible through the OBRA 1989 expansion to 8 percent for children made eligible through the OBRA 1990 expansion (and crowd-out effects insignificantly different from 0 in both cases). If the impact of the expansions differs, then $\beta$ is more correctly interpreted as an average of marginal effects, rather than a single marginal effect applicable to all 
children made eligible. The take-up and crowd-out propensities presented above would thus be an average of the propensities applying to individuals made eligible over the 1987-1992 period, which includes the implementation of the main federal expansions, OBRA 1989 and OBRA 1990.

Expansions by states beyond the federal minimum requirements are largely absent in the 1987-1992 period, however. In this section I present estimates from the 1987-1995 period (1988-1996 CPS). Including 1993-1995 incorporates more individuals affected by state expansions, as there was a large increase in eligibility due to state programs between 1992 and 1995 (see Table 2). ${ }^{15}$ The estimated average effect may differ once state programs are included. For example, if later expansions apply to individuals who are somewhat better off, then we might expect larger estimates of crowding out because more of these children have private coverage. Alternatively, we might expect smaller estimates of crowding out because better-off families are less informed about the potential eligibility of their children. The estimated average take-up rates are likely to change as well. Finally, including more years of data has the secondary effect of leading to an improvement in the precision of the estimates.

The results from the 1987-1995 sample are summarized in Table 4 for all children and for children with family incomes below 300 percent of the poverty line. As in Table 3 , the results do not differ substantially for the restricted and unrestricted samples. Using the Cutler-Gruber model, the estimated take-up rate is only about half the size of the estimated rate from the 19871992 data-between 14 and 16 percent. Once age by year interactions are included, the estimated take-up rate falls even further, to 3-4 percent. Adding a full set of two-way interactions to the

\footnotetext{
${ }^{15}$ The 1996 CPS is the last one used since it is the last CPS to be unaffected by welfare reform or the introduction of SCHIP.
} 
model increases the take-up rate to between 4 and 5 percent, but it is no longer statistically indistinguishable from 0 . The private coverage crowd-out rate from the Cutler-Gruber model is also somewhat lower than that estimated for 1987-1992. When interactions are included any evidence of crowding out disappears, with a coefficient that is actually positive, though insignificantly different from $0 .{ }^{16}$ It appears that the state expansions have even lower take-up and crowd-out rates than the earlier expansions, bringing the overall average estimates close to 0. It should be noted that a take-up estimate from the whole sample close to 0 does not mean that no expansion had an effect on take-up (the 15 percent take-up rate estimated for the earlier period shows this was not the case). Instead, it indicates that there was little to no new take-up among children who became eligible in the later years of the expansions. Thus the state optional expansions appear to have been even less effective than the earlier expansions at increasing health insurance coverage for low-income children.

\section{Implications of Measurement Error for Estimates of the Expansions' Impact}

The relatively low marginal estimated take-up rates for the expansions are puzzling when overall Medicaid enrollment trends are considered, as Medicaid enrollment rose steadily over the 1987-1993 period, from 15 percent of all children to 23 percent. A take-up rate of 0.15 can only explain 2 percentage points of the 8 percentage-point increase. One possible explanation is that take-up rates were actually higher, but measurement error in eligibility and/or Medicaid coverage caused the estimated take-up rates to be biased downward. Since both eligibility and Medicaid coverage are dichotomous variables, measurement error in either one will affect the consistency of the estimates.

\footnotetext{
${ }^{16}$ One possible explanation for the counterintuitive positive coefficient is that CPS respondents may mistake state programs and optional expansions for private coverage.
} 
To assess the extent to which the discrepancy between apparent take-up and new enrollment rates can be attributed to measurement error in eligibility, consider a simple model of the process generating observed eligibility status. Suppose that the probability a child is observed to be eligible given that he or she is truly eligible is a constant $q_{1}$, the probability a child is observed to be eligible given that he or she is actually ineligible (the false positive rate) is a constant $q_{0}$, and true eligibility status is uncorrelated with the error in the coverage equation. Then if the true fraction eligible is denoted $\pi$ and the observed fraction eligible denoted $p$, the reliability statistic in a model with no covariates is $\lambda^{\prime} \frac{\pi}{p} @_{(1 \& p)}^{\left(q_{1} \& p\right)}$ (see Card 1996). ${ }^{17}$ While $p$ is observable in the data (the mean over the $1987-1993$ period is 0.24 ), both $\pi$ and $q_{1}$ are unknown. Nevertheless, by making some plausible assumptions about $\pi$ and $q_{1}$ it is possible to derive a range of estimates about the degree of attenuation bias. A reasonable assumption is that $\pi=p$, that is, it is not the case that there are systematically more or fewer children eligible in the population, merely that which children are eligible has been misdetermined. I use the probability an individual is observed to be eligible given that he or she is observed to be receiving Medicaid (an average of 0.74 over the $1987-1993$ period) as the basis for a range of plausible values of $q_{1}$. A range of values of $q_{1}$ centered on 0.74 and the resulting estimates of $\lambda$ are shown in Table 5 . The reliability of the estimates ranges from 0.53 when $q_{1}$ is 0.64 , implying that estimates are roughly half their true size, to 0.79 when $q_{1}$ is 0.84 .

In the case of measurement error in Medicaid coverage, since the estimated model is a linear probability model, the coefficients will be attenuated by a factor $\mu^{\prime} 1 \& f_{n} \& f_{p}$, where $f_{n}$ is the false negative rate and $f_{p}$ is the false positive rate (see Card, Hildreth, and Shore-Sheppard

\footnotetext{
${ }^{17}$ The addition of covariates that are correlated with true eligibility status exacerbates the attenuation effect of the measurement error.
} 
2004). Both of these rates are unknown in the CPS, however Card, Hildreth, and ShoreSheppard estimate $\mu$ to be 0.85 among children in the Survey of Income and Program Participation (SIPP) using a sample consisting of SIPP data matched to administrative records from California. While the SIPP and CPS may have different error rates, 0.85 provides a plausible benchmark for determining attenuation bias due to mismeasured Medicaid receipt. Adjusted estimated take-up rates using a range of attenuation factors centered on 0.85 are presented in Table 5. For an estimated take-up rate of 0.15 , accounting for measurement error produces adjusted estimates of take-up in the range of 0.2 to 0.38 . If the true take-up rate was 0.2, 3 percentage points (of the 8 percentage-point increase in Medicaid coverage) can be attributed to the expansions, while if the true take-up rate was as high as $0.38,5$ percentage points of the increase can be attributed to the expansions. Thus even if measurement error is accounted for, a significant portion-between 38 and 63 percent-of the rise in Medicaid coverage remains unexplained. The substantial increase in Medicaid coverage unexplained by the expansions suggests that take-up among individuals already eligible for Medicaid was increasing over this period. It is possible that this increase was related to the expansions, perhaps because outreach efforts served to inform families of their children's eligibility, but this hypothesis is difficult to test.

\section{Summary and Conclusion}

In this paper I use data from the Current Population Survey to discern how the changes in Medicaid eligibility criteria that occurred as a result of federal and state legislation in the late 1980s and early 1990s affected Medicaid eligibility, enrollments, and private coverage in the population of children. I show graphically that the expansions had varying effects on children's 
eligibility over time, across ages, by age over time, across states, and within state over time, but that there was much less variation along all of these dimensions for both Medicaid and private coverage rates.

Reexamining the estimates of Cutler and Gruber (1996), the seminal paper in the literature, I find take-up rates for the period examined in their paper to be between 15 and 19 percent, and rates of private coverage crowd-out to be close to 0 . The substantially larger estimates found in their paper are due to their restrictive empirical specifications, which constrain trends in coverage to be the same by age. Other restrictions, including constraints on state trends and age by state effects, have little effect on the estimates. Similarly, using a lowincome subsample has little effect. Including later years in the estimation reduces the estimates of take-up and crowd-out propensities further, indicating that the state expansions occurring in those later years had little to no impact on insurance coverage of newly eligible children.

While few researchers have found statistically significant evidence of crowding out, many have found larger estimates of take-up than the unconstrained estimates presented here. It is clear that other trends must be adequately accounted for when attributing effects to the Medicaid expansions, and lack of such controls may explain higher estimated take-up rates. Since the propensity for an eligible individual to take-up Medicaid or to drop private coverage does not appear to be constant, but instead varies by source of eligibility, it is also possible that other researchers' findings of higher take-up rates incorporate sources of eligibility that yield higher take-up, such as eligibility through AFDC. In addition, few researchers have examined the period through 1995, when take-up rates among the newly eligible appear to have fallen.

Despite the substantial literature focused on the effect of the Medicaid expansions, several important questions remain unanswered. The evidence that take-up rates were both low 
and varying indicates that design of public health insurance provision is crucial to its success. Research is needed on why the impact of the expansions varied, and what effect that variation had on children's access to care and health outcomes. This is particularly true when attempting to evaluate the SCHIP expansions, which were even more variable in design than the Medicaid expansions. The SCHIP expansions are also potentially more difficult to evaluate, as states were given block grants and allowed considerable freedom to design their own programs. Consequently, concerns about the endogeneity of state legislation are especially relevant. Finally, between 1987 and 1992 there was a 4.5 percentage-point fall in private insurance coverage among children. Adding the years 1993-1995 increases this estimate to 7.6 percentage points. Since little to none of this coverage loss appears to be due to the expansions, the question of the primary causes of private coverage losses remains. 


\section{$\underline{\text { References }}$}

Blumberg, Linda J., Lisa Dubay, and Stephen A. Norton. 2000. "Did the Medicaid Expansions for Children Displace Private Insurance? An Analysis Using the SIPP." Journal of Health Economics 19(1): 33-60.

Card, David. 1996. "The Effect of Unions on the Structure of Wages: A Longitudinal Analysis." Econometrica 64(4): 957-979.

and Lara D. Shore-Sheppard. 2004. "Using Discontinuous Eligibility Rules to Identify the Effects of the Federal Medicaid Expansions on Low Income Children." Review of Economics and Statistics 86(3): 752-766.

, Andrew Hildreth, and Lara D. Shore-Sheppard. 2004. "The Measurement of Medicaid Coverage in the SIPP: Evidence from a Matched Record Comparison." Journal of Business and Economic Statistics 22(4): 410-420.

Cutler, David M. and Jonathan Gruber. 1996. "Does Public Insurance Crowd out Private Insurance?" Quarterly Journal of Economics 111(2): 391-430.

Dubay, Lisa C. and Genevieve Kenney. 1996. "The Effects of the Medicaid Expansions on Insurance Coverage of Children." The Future of Children 6(1): 152-161.

Ham, John C. and Lara D. Shore-Sheppard. 2005. "The Effect of Medicaid Expansions for Low-Income Children on Medicaid Participation and Private Insurance Coverage: Evidence from the SIPP.” Journal of Public Economics 89(1): 57-83.

Ku, Leighton, Marilyn Rymer Ellwood, and John Klemm. 1990. "Deciphering Medicaid Data: Issues and Needs." Health Care Financing Review (Annual Supplement).

National Governors' Association Center for Policy Research. 1988-1996. "State Coverage of Pregnant Women and Children." Washington, DC: National Governors' Association. Unpublished reports.

Office of Technology Assessment. 1988. Healthy Children: Investing in the Future. Washington, DC: U.S. Government Printing Office.

Shore-Sheppard, Lara D. 1996a. "Medicaid and Health Insurance for Children: Essays in Empirical Economics." Unpublished Ph. D. Dissertation. Princeton University.

. 1996b. "The Precision of Instrumental Variables Estimates With Grouped Data." Princeton University Industrial Relations Section Working Paper \#374.

. 2000. "The Effect of Expanding Medicaid Eligibility on the Distribution of Children's Health Insurance Coverage." Industrial and Labor Relations Review 54(1): 59-77. 
Swartz, Katherine. 1986. "Interpreting the Estimates from Four National Surveys of the Number of People Without Health Insurance." Journal of Economic and Social Measurement 14(3): 233-242. . 1996. "Medicaid Crowd Out and the Inverse Truman Bind." Inquiry 33(1): 5-8. . 1997. "Changes in the 1995 Current Population Survey and Estimates of Health Insurance Coverage.” Inquiry 34(1): 70-79.

U. S. House of Representatives Committee on Ways and Means. 1986-1991, 1993. Green Book: Background Material and Data on Programs Within the Jurisdiction of the Committee on Ways and Means. Washington, DC: U.S. Government Printing Office.

U. S. Census Bureau. 2003. Statistical Abstract of the United States: 2003. Washington, DC: U.S. Government Printing Office.

Yazici, Ezel and Robert Kaestner. 2000. "Medicaid Expansions and the Crowding Out of Private Health Insurance Among Children." Inquiry 37(1): 23-32. 
Appendix Table 1: Summary of Federal Legislation Related to Medicaid Coverage for Pregnant Women, Infants, and Children, $1986-1990$.

\section{Omnibus Budget Reconciliation Act (OBRA) 1986. Effective: April 1987.}

Optional: States may raise the income eligibility threshold above AFDC levels to as high as the Federal poverty level for pregnant women, infants, and children up to 5 years of age, even if the principal earner is employed. (Children may be phased in gradually.)

\section{Omnibus Budget Reconciliation Act (OBRA) 1987. Effective: July 1988.}

Required: States must cover all children under age 7 born after 9/30/83 who meet income and resource standards for AFDC, regardless of family structure.

Optional: States may raise income thresholds for pregnant women and infants to $185 \%$ of the Federal poverty level. States may cover children under age $2,3,4$, or 5 who were born after 9/30/83 with incomes below the Federal poverty level.

\section{Medicare Catastrophic Coverage Act (MCCA). Effective: July 1989.}

Required: States must cover pregnant women and infants with incomes less than or equal to $75 \%$ of the poverty level (it was to move to $100 \%$ by the following year, but was superseded by OBRA 1989)

Optional: States may cover children up to 8 years of age with incomes less than or equal to $75 \%$ of the poverty level.

\section{Family Support Act (FSA) 1988. Effective: October 1990.}

Required: States must extend Medicaid coverage to eligible 2-parent families where the principal earner is unemployed.

\section{Omnibus Budget Reconciliation Act (OBRA) 1989. Effective: April 1990.}

Required: States must cover pregnant women and children under age 6 with family incomes up to $133 \%$ of the Federal poverty level.

\section{Omnibus Budget Reconciliation Act (OBRA) 1990. Effective: July 1991}

Required: States must cover children under age 19 who were born after 9/30/83 whose family income level is below $100 \%$ of the poverty level. States must continue benefits for pregnant women until 2 months after the end of pregnancy, and for infants through the first year of life.

Sources: U. S. House of Representatives Committee on Ways and Means (1986-1991, 1993), National Governors' Association Center for Policy Research (1988-1996). 
Table 1: Sample Fractions, Children 18 and Under

\begin{tabular}{|c|c|c|c|c|c|c|c|c|c|}
\hline $\begin{array}{r}\text { Survey year } \\
\text { (reference year) }\end{array}$ & $\begin{array}{c}1988 \mathrm{CPS} \\
(1987)\end{array}$ & $\begin{array}{l}1989 \text { CPS } \\
(1988)\end{array}$ & $\begin{array}{l}1990 \mathrm{CPS} \\
(1989)\end{array}$ & $\begin{array}{l}1991 \mathrm{CPS} \\
(1990)\end{array}$ & $\begin{array}{l}1992 \mathrm{CPS} \\
(1991)\end{array}$ & $\begin{array}{c}1993 \text { CPS } \\
(1992)\end{array}$ & $\begin{array}{c}1994 \mathrm{CPS} \\
(1993)\end{array}$ & $\begin{array}{c}1995 \text { CPS } \\
(1994)\end{array}$ & $\begin{array}{c}1996 \mathrm{CPS} \\
(1995)\end{array}$ \\
\hline Medicaid recipient & 0.148 & 0.151 & 0.153 & 0.180 & 0.199 & 0.210 & 0.233 & 0.224 & 0.227 \\
\hline Private coverage & 0.739 & 0.736 & 0.736 & 0.713 & 0.698 & 0.694 & 0.675 & 0.660 & 0.663 \\
\hline No insurance & 0.130 & 0.133 & 0.135 & 0.132 & 0.129 & 0.128 & 0.140 & 0.143 & 0.141 \\
\hline Age $<=2$ & 0.166 & 0.168 & 0.170 & 0.173 & 0.172 & 0.171 & 0.168 & 0.163 & 0.161 \\
\hline Age 3-5 & 0.163 & 0.164 & 0.166 & 0.165 & 0.166 & 0.167 & 0.168 & 0.170 & 0.167 \\
\hline Age 6-8 & 0.162 & 0.163 & 0.163 & 0.162 & 0.161 & 0.161 & 0.158 & 0.159 & 0.160 \\
\hline Age 9-11 & 0.153 & 0.157 & 0.160 & 0.162 & 0.163 & 0.161 & 0.161 & 0.159 & 0.159 \\
\hline Age $12-14$ & 0.147 & 0.147 & 0.149 & 0.150 & 0.153 & 0.155 & 0.156 & 0.157 & 0.156 \\
\hline Age $15-18$ & 0.209 & 0.201 & 0.193 & 0.188 & 0.185 & 0.185 & 0.189 & 0.192 & 0.196 \\
\hline Northeast & 0.186 & 0.191 & 0.192 & 0.193 & 0.190 & 0.185 & 0.186 & 0.184 & 0.186 \\
\hline Midwest & 0.250 & 0.251 & 0.244 & 0.243 & 0.245 & 0.247 & 0.241 & 0.240 & 0.237 \\
\hline South & 0.350 & 0.348 & 0.341 & 0.342 & 0.338 & 0.345 & 0.343 & 0.349 & 0.343 \\
\hline West & 0.214 & 0.211 & 0.223 & 0.222 & 0.226 & 0.224 & 0.231 & 0.227 & 0.234 \\
\hline Two parent family & 0.738 & 0.739 & 0.735 & 0.728 & 0.717 & 0.715 & 0.710 & 0.706 & 0.696 \\
\hline Female head & 0.220 & 0.219 & 0.222 & 0.227 & 0.238 & 0.238 & 0.240 & 0.243 & 0.249 \\
\hline Male head & 0.033 & 0.034 & 0.036 & 0.036 & 0.037 & 0.039 & 0.039 & 0.042 & 0.046 \\
\hline Pct. of pov. level: & & & & & & & & & \\
\hline$<50 \%$ & 0.104 & 0.101 & 0.096 & 0.102 & 0.110 & 0.115 & 0.113 & 0.109 & 0.098 \\
\hline $50 \%-74 \%$ & 0.059 & 0.054 & 0.055 & 0.060 & 0.065 & 0.061 & 0.071 & 0.065 & 0.066 \\
\hline $75 \%-99 \%$ & 0.051 & 0.049 & 0.057 & 0.056 & 0.055 & 0.054 & 0.057 & 0.056 & 0.056 \\
\hline $100 \%-133 \%$ & 0.069 & 0.070 & 0.069 & 0.070 & 0.072 & 0.071 & 0.075 & 0.074 & 0.078 \\
\hline $133 \%-185 \%$ & 0.102 & 0.109 & 0.106 & 0.113 & 0.115 & 0.110 & 0.111 & 0.109 & 0.111 \\
\hline $185 \%-300 \%$ & 0.233 & 0.234 & 0.230 & 0.237 & 0.229 & 0.224 & 0.218 & 0.219 & 0.218 \\
\hline$>=300 \%$ & 0.382 & 0.382 & 0.388 & 0.362 & 0.356 & 0.364 & 0.355 & 0.368 & 0.372 \\
\hline $\begin{array}{l}\text { Children in family } \\
\text { receiving AFDC }\end{array}$ & 0.112 & 0.111 & 0.108 & 0.123 & 0.132 & 0.131 & 0.134 & 0.125 & 0.120 \\
\hline Sample size & 45048 & 41423 & 45305 & 45584 & 44461 & 44600 & 43932 & 43440 & 38171 \\
\hline
\end{tabular}

Notes: The data are from the Current Population Survey March supplements 1988-1996. The fractions are weighted by the CPS March supplement weight. 
Table 2: Eligibility of a Constant Population, by Source

\begin{tabular}{|c|c|c|c|c|c|c|}
\hline & & \multicolumn{5}{|c|}{ Eligibility by Source (Percent) } \\
\hline Year & $\begin{array}{c}\text { Total } \\
\text { (Percent) }\end{array}$ & AFDC & MCCA & $\begin{array}{c}\text { OBRA } \\
1989\end{array}$ & $\begin{array}{c}\text { OBRA } \\
1990\end{array}$ & $\begin{array}{c}\text { State } \\
\text { program }\end{array}$ \\
\hline 1987 & 17.5 & 17.4 & 0 & 0 & 0 & 0.1 \\
\hline 1988 & 17.8 & 17.2 & 0 & 0 & 0 & 0.6 \\
\hline 1989 & 18.8 & 17.4 & 0.1 & 0 & 0 & 1.3 \\
\hline 1990 & 22.2 & 17.5 & 0.2 & 3.6 & 0 & 0.8 \\
\hline 1991 & 23.9 & 17.4 & 0.2 & 4.9 & 0.5 & 0.8 \\
\hline 1992 & 25.2 & 17.1 & 0.3 & 5.0 & 1.7 & 1.2 \\
\hline 1993 & 28.7 & 16.8 & 0.3 & 5.1 & 2.2 & 4.3 \\
\hline 1994 & 29.6 & 16.7 & 0.3 & 5.1 & 2.7 & 4.8 \\
\hline 1995 & 29.1 & 16.5 & 0.3 & 5.2 & 3.2 & 3.9 \\
\hline
\end{tabular}

Notes: Constant population is population from 1988 CPS. "AFDC" category includes all programs where the child must meet AFDC income standards, including AFDC, AFDC-UP, Ribicoff kids, and the expansions under DEFRA of 1984. 
Table 3: Re-analysis of Cutler-Gruber (1996) Models

\begin{tabular}{|c|c|c|c|}
\hline Dependent variable: & $\begin{array}{l}\text { Covered by } \\
\text { Medicaid }\end{array}$ & $\begin{array}{c}\text { Covered by } \\
\text { Private Insurance }\end{array}$ & Uninsured \\
\hline \multicolumn{4}{|c|}{ A. $1987-1992$ (1988-1993 CPS), all children 18 and under: } \\
\hline $\begin{array}{l}\text { Cutler and Gruber (1996) } \\
\text { Table IV }\end{array}$ & $\begin{array}{c}0.235 \\
(0.017)\end{array}$ & $\begin{array}{l}-0.074 \\
(0.021)\end{array}$ & $\begin{array}{l}-0.119 \\
(0.018)\end{array}$ \\
\hline Replication & $\begin{array}{c}0.250 \\
(0.016)\end{array}$ & $\begin{array}{l}-0.059 \\
(0.020)\end{array}$ & $\begin{array}{l}-0.135 \\
(0.018)\end{array}$ \\
\hline With state $\times$ year dummies & $\begin{array}{c}0.282 \\
(0.017)\end{array}$ & $\begin{array}{l}-0.075 \\
(0.022)\end{array}$ & $\begin{array}{l}-0.142 \\
(0.019)\end{array}$ \\
\hline With age $\times$ year dummies & $\begin{array}{c}0.145 \\
(0.025)\end{array}$ & $\begin{array}{l}-0.005 \\
(0.031)\end{array}$ & $\begin{array}{l}-0.098 \\
(0.026)\end{array}$ \\
\hline With age $\times$ state dummies & $\begin{array}{c}0.250 \\
(0.017)\end{array}$ & $\begin{array}{l}-0.057 \\
(0.022)\end{array}$ & $\begin{array}{l}-0.134 \\
(0.019)\end{array}$ \\
\hline $\begin{array}{l}\text { With age } \times \text { year, age } \times \text { state, } \\
\text { and state } \times \text { year dummies }\end{array}$ & $\begin{array}{c}0.193 \\
(0.042)\end{array}$ & $\begin{array}{l}-0.012 \\
(0.054)\end{array}$ & $\begin{array}{l}-0.079 \\
(0.046)\end{array}$ \\
\hline \multicolumn{4}{|c|}{ B. $1987-1992$ (1988-1993 CPS), children 18 and under with incomes $<300 \%$ of poverty } \\
\hline Cutler-Gruber model & $\begin{array}{c}0.222 \\
(0.016)\end{array}$ & $\begin{array}{l}-0.040 \\
(0.020)\end{array}$ & $\begin{array}{l}-0.136 \\
(0.017)\end{array}$ \\
\hline With state $\times$ year dummies & $\begin{array}{c}0.253 \\
(0.018)\end{array}$ & $\begin{array}{l}-0.060 \\
(0.021)\end{array}$ & $\begin{array}{l}-0.140 \\
(0.019)\end{array}$ \\
\hline With age $\times$ year dummies & $\begin{array}{c}0.130 \\
(0.026)\end{array}$ & $\begin{array}{c}0.020 \\
(0.030)\end{array}$ & $\begin{array}{l}-0.113 \\
(0.025)\end{array}$ \\
\hline With age $\times$ state dummies & $\begin{array}{c}0.218 \\
(0.018)\end{array}$ & $\begin{array}{l}-0.037 \\
(0.021)\end{array}$ & $\begin{array}{l}-0.132 \\
(0.019)\end{array}$ \\
\hline $\begin{array}{l}\text { With age } \times \text { year, age } \times \text { state, } \\
\text { and state } \times \text { year dummies }\end{array}$ & $\begin{array}{c}0.151 \\
(0.045)\end{array}$ & $\begin{array}{c}0.011 \\
(0.055)\end{array}$ & $\begin{array}{l}-0.076 \\
(0.047)\end{array}$ \\
\hline
\end{tabular}

Notes: Standard errors in parentheses. Entries are the coefficients on imputed Medicaid eligibility from instrumental variables regressions, using the percentage of a national sample simulated to be eligible in each state-year-age cell as the instrument. Models include the number of people in the family and dummies for age, state, year, male, white, household head type, and number of workers. 
Table 4: Full Sample Estimates of Take-Up and Crowd-Out

\begin{tabular}{|c|c|c|c|}
\hline Dependent variable: & $\begin{array}{l}\text { Covered by } \\
\text { Medicaid }\end{array}$ & $\begin{array}{c}\text { Covered by } \\
\text { Private Insurance }\end{array}$ & Uninsured \\
\hline \multicolumn{4}{|c|}{ A. $1987-1995$ (1988-1996 CPS), all children 18 and under: } \\
\hline Cutler-Gruber model & $\begin{array}{c}0.157 \\
(0.011)\end{array}$ & $\begin{array}{l}-0.045 \\
(0.014)\end{array}$ & $\begin{array}{l}-0.065 \\
(0.012)\end{array}$ \\
\hline With age $\times$ year dummies & $\begin{array}{c}0.037 \\
(0.015)\end{array}$ & $\begin{array}{c}0.004 \\
(0.018)\end{array}$ & $\begin{array}{l}-0.013 \\
(0.015)\end{array}$ \\
\hline $\begin{array}{l}\text { With age } \times \text { year, age } \times \text { state, } \\
\text { and state } \times \text { year dummies }\end{array}$ & $\begin{array}{c}0.049 \\
(0.032)\end{array}$ & $\begin{array}{c}0.077 \\
(0.039)\end{array}$ & $\begin{array}{l}-0.096 \\
(0.032)\end{array}$ \\
\hline \multicolumn{4}{|c|}{ B. $1987-1995$ (1988-1996 CPS), children 18 and under with incomes $<300 \%$ of poverty } \\
\hline Cutler-Gruber model & $\begin{array}{c}0.136 \\
(0.011)\end{array}$ & $\begin{array}{l}-0.019 \\
(0.013)\end{array}$ & $\begin{array}{l}-0.070 \\
(0.012)\end{array}$ \\
\hline With age $\times$ year dummies & $\begin{array}{c}0.032 \\
(0.014)\end{array}$ & $\begin{array}{c}0.028 \\
(0.016)\end{array}$ & $\begin{array}{l}-0.028 \\
(0.014)\end{array}$ \\
\hline $\begin{array}{l}\text { With age } \times \text { year, age } \times \text { state, } \\
\text { and state } \times \text { year dummies }\end{array}$ & $\begin{array}{c}0.044 \\
(0.029)\end{array}$ & $\begin{array}{c}0.058 \\
(0.034)\end{array}$ & $\begin{array}{l}-0.083 \\
(0.028)\end{array}$ \\
\hline
\end{tabular}

Notes: Standard errors in parentheses. Entries are the coefficients on imputed Medicaid eligibility from instrumental variables regressions, using the percentage of a national sample simulated to be eligible in each state-year-age cell as the instrument. Models include the number of people in the family and dummies for age, state, year, male, white, household head type, and number of workers. 
Table 5: Estimates of Take-up Accounting for Measurement Error

\begin{tabular}{l|c|ccc}
\hline & & \multicolumn{3}{|c}{ Estimated take-up rate $=0.15$} \\
\cline { 3 - 5 } Assumed P(obs. eligible | truly eligible) & Reliability $(\lambda)$ & $\mu=0.75$ & $\mu=0.85$ & $\mu=0.95$ \\
\hline$q_{1}=0.64$ & 0.53 & 0.38 & 0.34 & 0.3 \\
$q_{1}=0.74$ & 0.66 & 0.30 & 0.27 & 0.24 \\
$q_{1}=0.84$ & 0.79 & 0.25 & 0.22 & 0.2 \\
\hline
\end{tabular}

Notes: Entries in columns 3-5 are estimated take-up rates under the specified hypotheses about measurement error in Medicaid eligibility and coverage. 
Figure 1: Medicaid Eligibility Of Children, 1987-1995

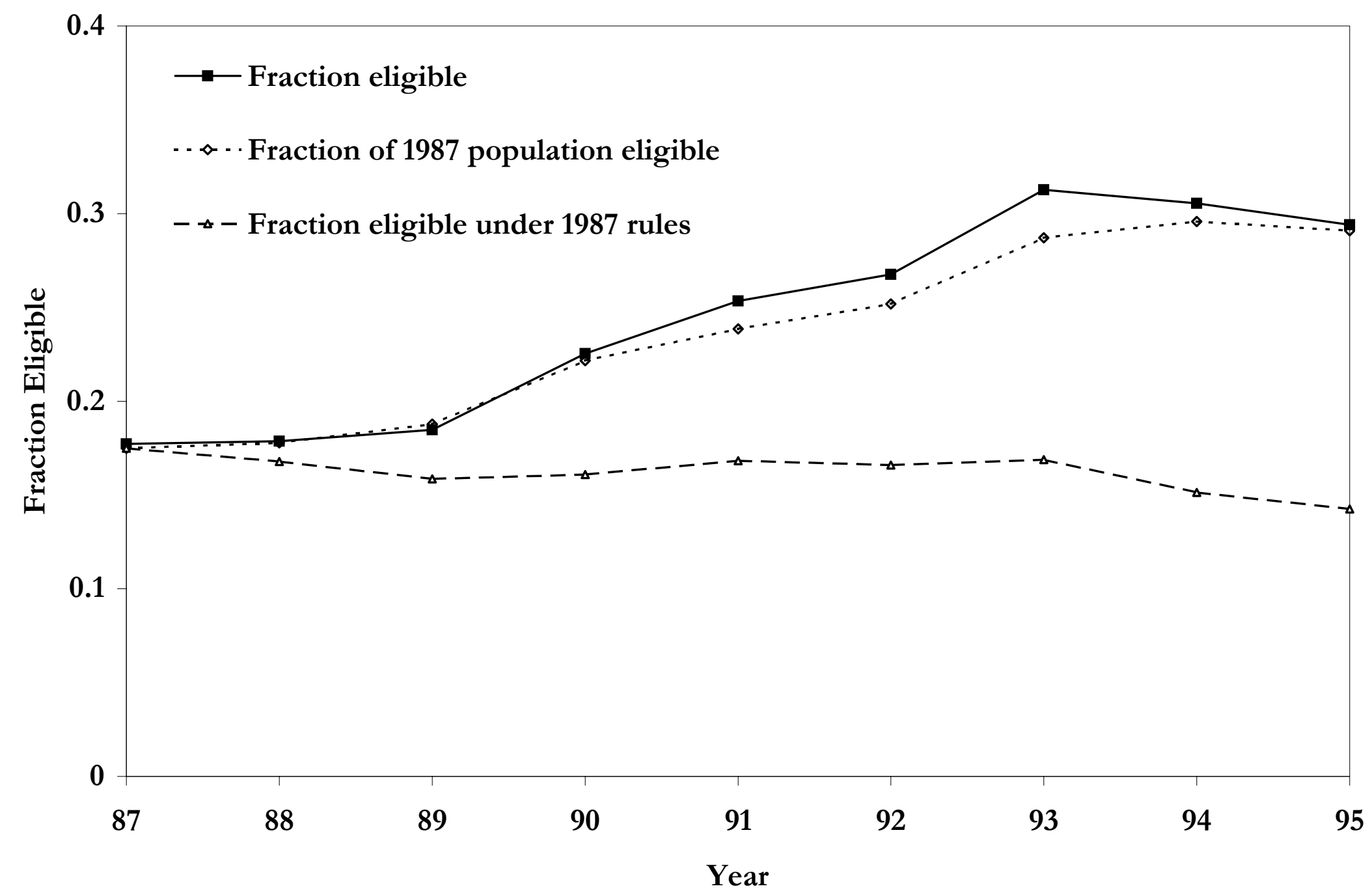


Figure 2: Medicaid Eligibility, by Age

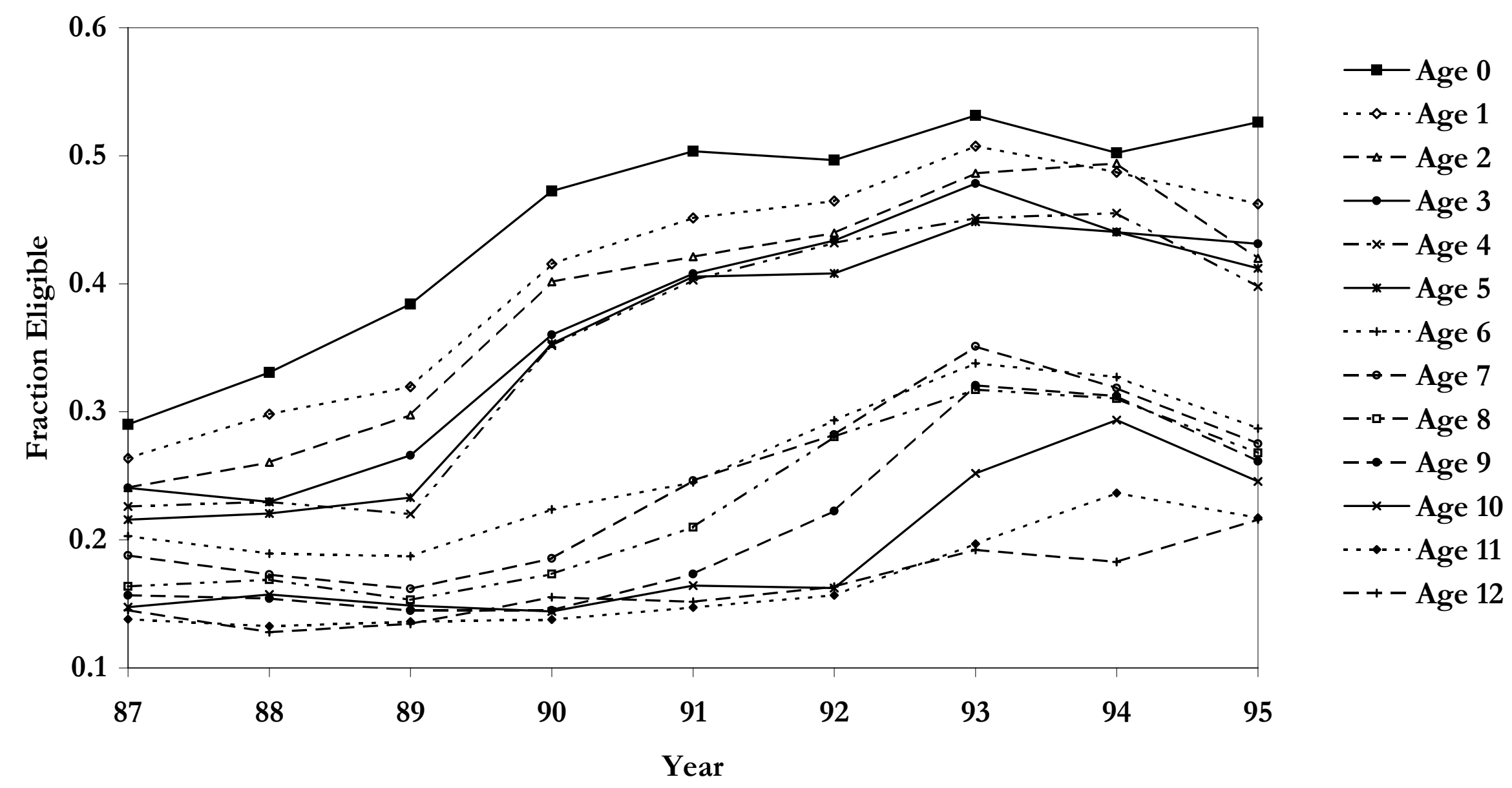


Figure 3: Medicaid Coverage, by Age

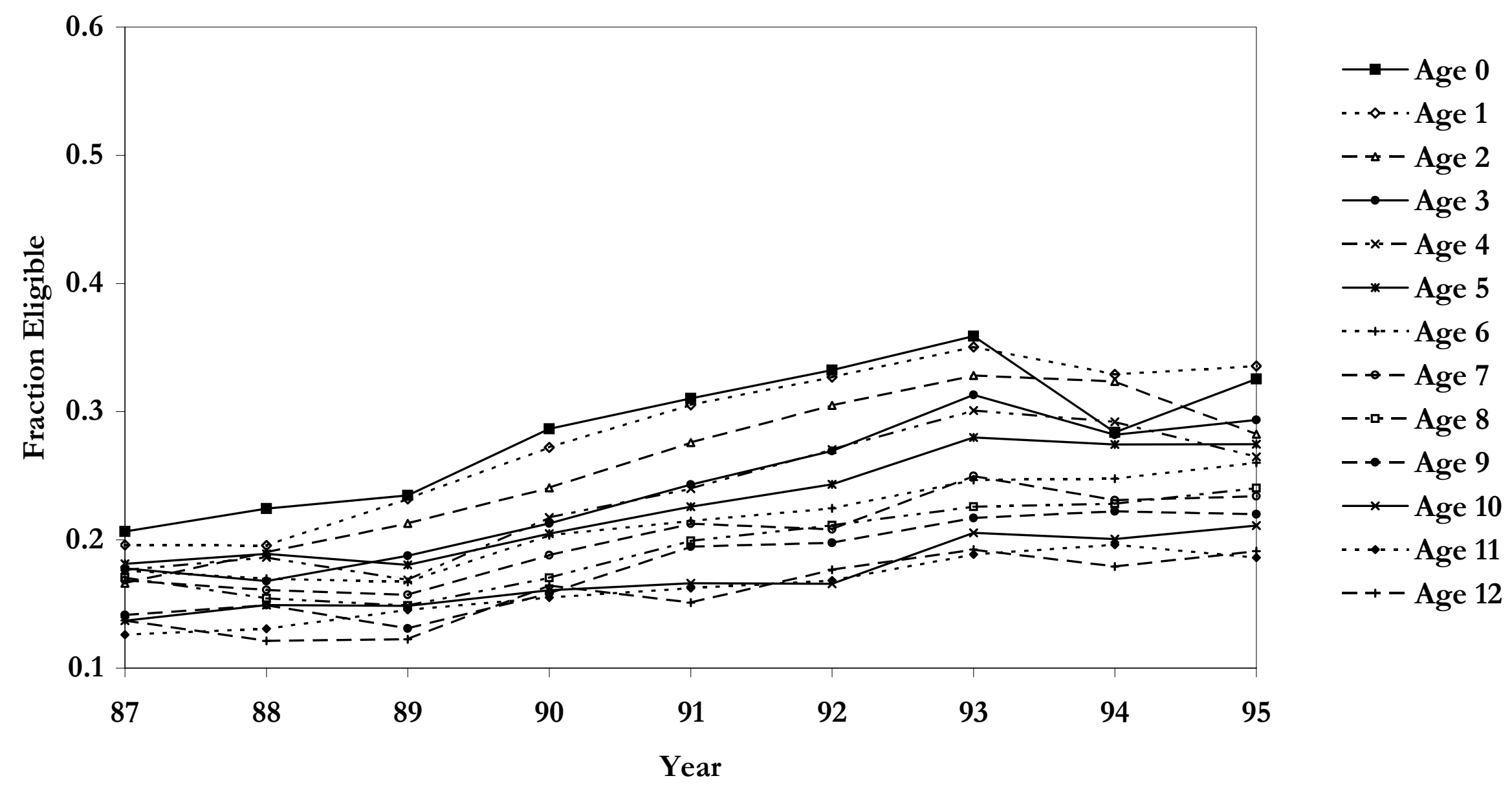


Figure 4: Medicaid Eligibility by State for 5 Populous States

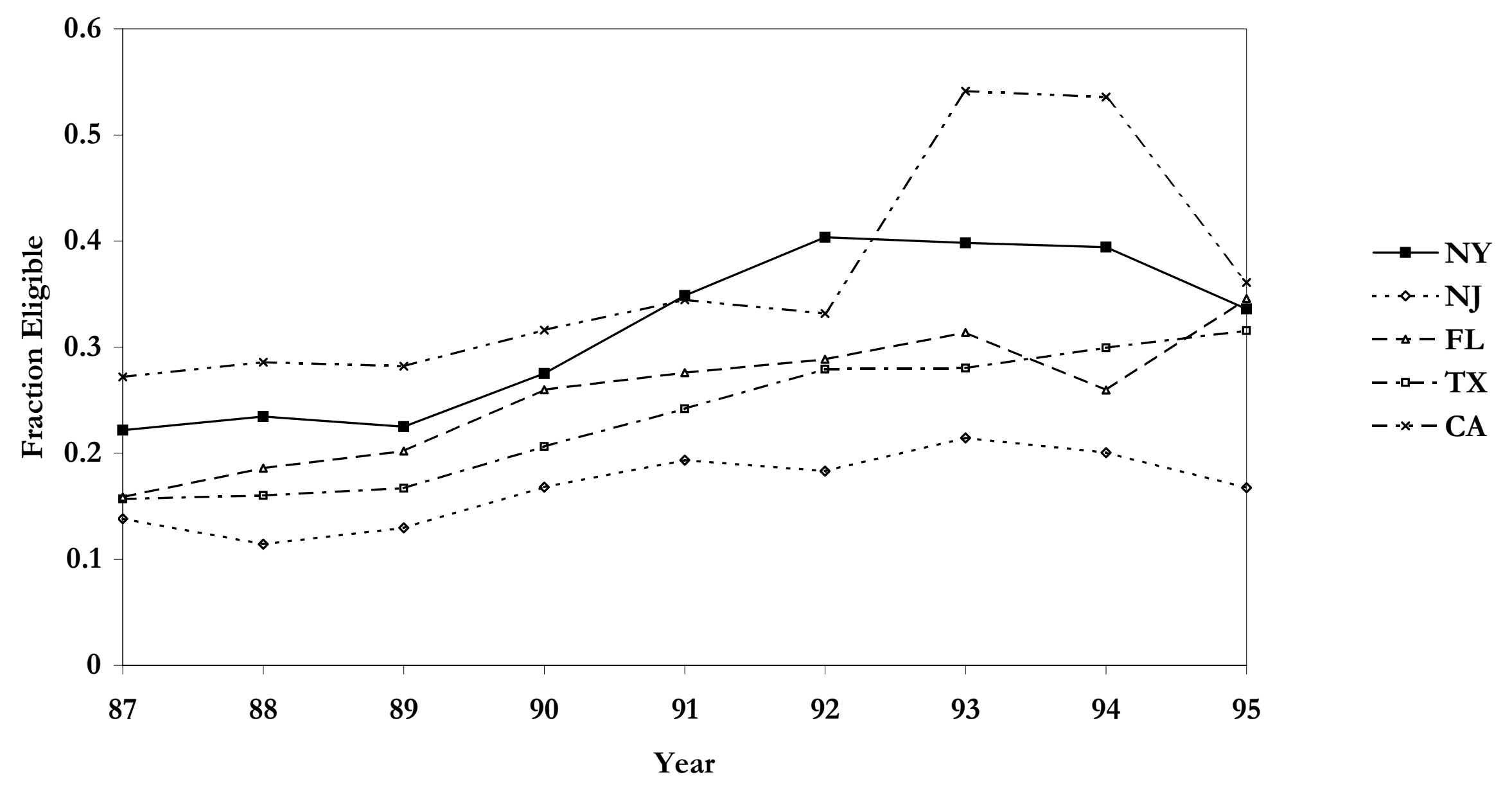


Figure 5: Medicaid Coverage by State for 5 Populous States

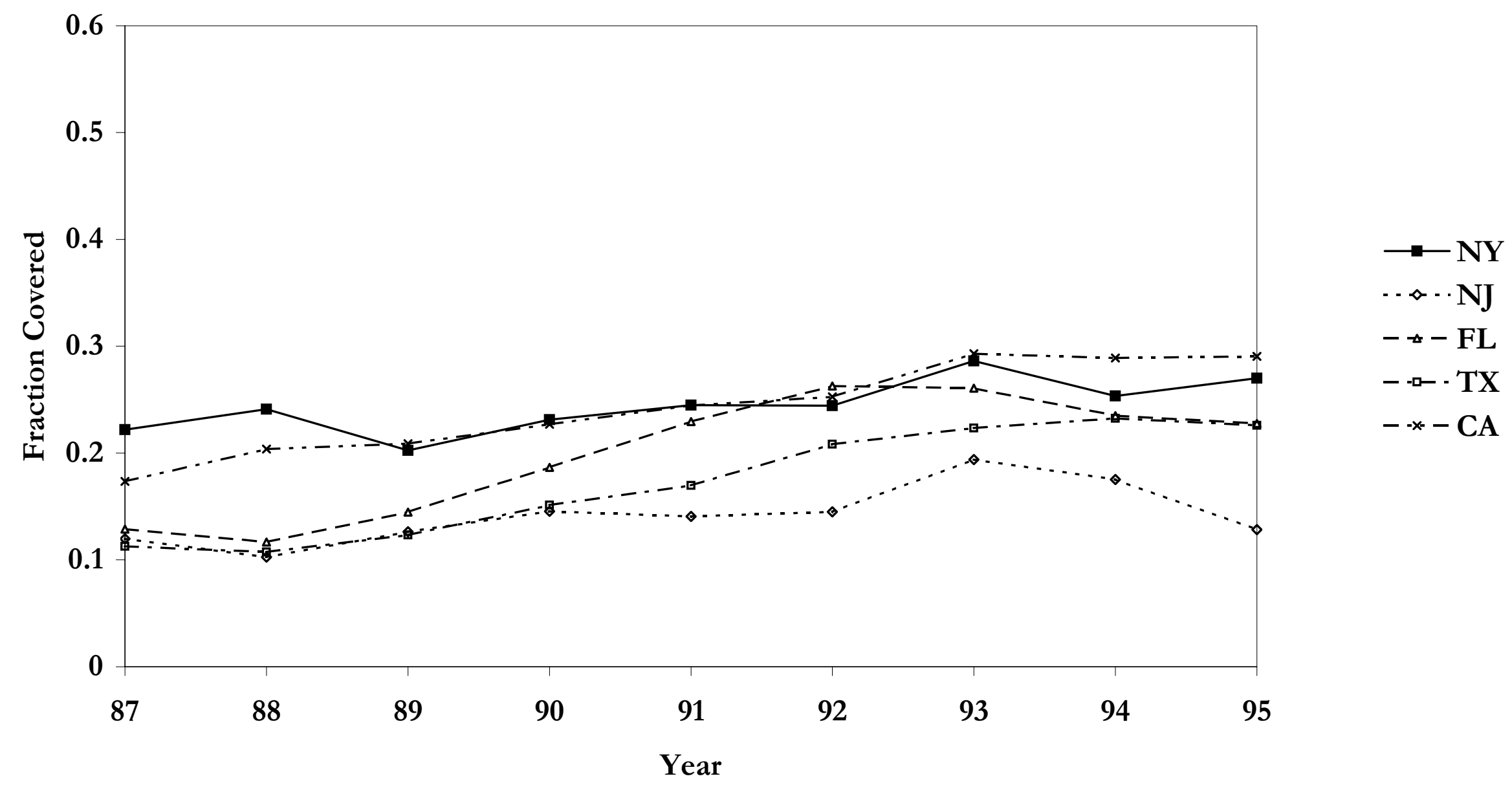

